\title{
ESTADO DO CONHECIMENTO SOBRE OS ABANDONOS NA LICENCIATURA E NA DOCÊNCIA NAS ÁREAS DE CIÊNCIAS E MATEMÁTICA
}

\author{
STATE OF KNOWLEDGE ABOUT DROPOUTS IN DEGREE COURSE AND \\ TEACHING IN THE AREAS OF SCIENCE AND MATHEMATICS
}

\author{
Deise Nivia Reisdoefer ${ }^{1}$ \\ Rosana Maria Gessinger ${ }^{2}$ \\ Valderez Marina do Rosário Lima ${ }^{3}$
}

\begin{abstract}
Resumo
Este artigo apresenta o estado de conhecimento realizado a partir de pesquisa de teses, dissertações e artigos com enfoque nos abandonos que ocorrem na licenciatura e na docência. Tem como objetivo compreender algumas das (des)motivações que contribuem para o abandono da carreira docente, seja durante a atuação ou anterior à ela, já nos cursos de licenciatura. A identificação de algumas confluências entre as pesquisas evidencia que nos cursos de licenciatura o abandono é justificado a partir: dos motivos pela escolha da licenciatura; do perfil do evadido ou daquele que possivelmente evadirá; das causas pessoais do licenciando em relação ao abandono; do discurso do docente formador desses acadêmicos; das disciplinas ou do curso como causas de desistência; dos problemas em relação à instituição de ensino; da falta ou inadequação de políticas públicas. Já na docência, as motivações para o abandono permeiam: uma visão neoliberal de um Estado que não valoriza a Educação e, portanto, à docência; as adversidades na formação inicial; problemas de estrutura física e pedagógica das escolas; as condições sociais ou particulares, que afetam ou são afetadas pelo abandono da sala de aula.
\end{abstract}

1 A autora é doutoranda em Educação em Ciências e Matemática - PUCRS. Professora do Instituto Federal Catarinense - Campus Concórdia. Membro do GEMat (Grupo de Pesquisa em Educação Matemática).E-mail: dnreisdoefer@hotmail.com

${ }^{2}$ A autora é doutora em Educação e Professora Adjunta da PUCRS. Membro GPEAI - Grupo de Pesquisas em Ensino nos Anos Iniciais. E-mail: rosana.gessinger@pucrs.br

${ }^{3}$ A autora é doutora em Educação e Professora Adjunta da PUCRS. Líder do Grupo de Pesquisa do CNPQ "Ensino, Aprendizagem e formação de professores de Ciências: desafios para o século XXI". E-mail: valderez.lima@pucrs.br 
Palavras-chave: Abandono. Desmotivações. Licenciatura. Docência.

\begin{abstract}
This paper presents the state of knowledge realized from research of theses, dissertations and papers focusing on the dropouts that occur in undergraduate and teaching. It aims to understand some of the (dis) motivations that contribute to the abandonment of the teaching career, either during or before the performance, in undergraduate courses. The identification of some confluences between the researches shows that in the degree courses the abandonment is justified from: the reasons for the choice of the degree; The profile of the evader or the one who is likely to evade; Of the licensee's personal causes in relation to abandonment; Of the discourse of the educating teacher of these academics; Disciplines or the course as causes of withdrawal; Problems with the educational institution; And the lack or inadequacy of public policies. Already in the teaching the motivations for the abandonment permeate: neoliberal vision of a State that does not value the Education and, therefore, the teaching; Adversities in initial training; Problems of physical and pedagogical structure of schools; the social or particular conditions that affect or are affected by the abandonment of the classroom.
\end{abstract}

Key-words: Abandonment. Demotivations. Degree Course. Teaching.

\title{
Introdução
}

O abandono na docência e nos cursos de licenciatura na área das Ciências e Matemática é o tema central deste estudo. Trata-se de um fenômeno atual e preocupante, cujas consequências para a sociedade poderão ser bastante graves no decorrer do tempo. De fato, em nosso percurso como formadoras de professores, no convivio cotidiano com licenciandos e docentes, observamos com apreensão as altas taxas de evasão, tanto na licenciatura quanto na docência.

Pesquisas como as de Vitelli (2013) e Fonseca (2013), por exemplo, abordam esta problemática. Para melhor compreendê-la, optamos por realizar uma pesquisa do tipo estado de conhecimento, buscando apoio nas ideias de Romanovski e Ens (2006, p. 4), que afirmam que esse tipo de busca/pesquisa possibilita 
[...] uma contribuição importante na constituição do campo teórico de uma área de conhecimento, pois procuram identificar os aportes significativos da construção da teoria e prática pedagógica, apontar as restrições sobre o campo em que se move a pesquisa, as suas lacunas de disseminação, identificar experiências inovadoras investigadas que apontem alternativas de solução para os problemas da prática e reconhecer as contribuições da pesquisa na constituição de propostas na área focalizada.

A elaboração do estado de conhecimento, além de apresentar trabalhos já realizados sobre o tema, permite a compreensão da problemática proposta ao fornecer um panorama geral do que está sendo pesquisado sobre o tema, discutindo os conhecimentos construidos e, também, as lacunas que poderiam ser preenchidas. Além disso, possibilita avanços nas pesquisas da área em detrimento da reprodução de algo que já foi produzido anteriormente, aspecto abordado por Morosini (2015, p. 107), quando afirma que "[...] além de revermos os apoios teóricos que fundamentam nossa temática, buscamos identificar o que já foi produzido em matéria de pesquisa sobre a mesma".

Desse modo, a problemática que impulsiona a elaboração deste estado de conhecimento pode ser assim enunciada: o que se tem produzido acerca do tema evasão na docência e evasão na licenciatura, e quais são as principais contribuições destes estudos na área das Ciências e da Matemática?

Assim, esta investigação tem como objetivo produzir o estado de conhecimento das pesquisas sobre evasão, de modo a compreender algumas (des)motivações que contribuem para o abandono da carreira docente, seja durante a atuação ou anterior à ela, já nos cursos de licenciatura.

$\mathrm{Na}$ sequência, descrevemos a forma como a busca foi realizada, bem como o aporte teórico utilizado. Como corpus central do artigo, apresentamos as análises a partir dos trabalhos criteriosamente selecionados.

\section{O Percurso Metodológico}

Com o intuito de produzir o estado de conhecimento e compreender as motivações sobre os abandonos ocorridos na licenciatura e na docência, 
estabelecemos como critérios de busca dois recortes: a evasão, desistência ou abandono na licenciatura; a evasão, abandono ou desistência na docência ou na carreira docente ou no magistério, focando nos aspectos da formação profissional do professor de Matemática. Para Soares (apud ROMANOVSKI; ENS, 2006, p. 4), “[...] pesquisas desse tipo é que podem conduzir à plena compreensão do estado atingido pelo conhecimento a respeito de determinado tema - sua amplitude, tendências teóricas e vertentes metodológicas”.

Portanto, por meio da pesquisa de artigos, teses e dissertações no portal da Coordenação de Aperfeiçoamento de Pessoal de Nivel Superior (Capes), na Biblioteca Digital de Teses e Dissertações (BDTD) e no Google Acadêmico, realizamos a construção do estado de conhecimento, baseando-nos na perspectiva de Morosini (2015, p. 102):

[...] estado de conhecimento é identificação, registro, categorização que levem à reflexão e sintese sobre a produção científica de uma determinada área, em um determinado espaço de tempo, congregando periódicos, teses, dissertações e livros sobre uma temática específica.

Ao iniciarmos a busca, poucos trabalhos foram encontrados, levandonos a retirar como critério a palavra Matemática. Obtivemos, então, como resultado inicial, 448 produções acadêmicas. Desse número inicial de produções encontradas, foram selecionadas, por meio da observação dos títulos, as produções que tratavam do assunto pesquisado. Nessa etapa, muitos trabalhos apareceram repetidas vezes. Depois de realizada a análise dos títulos, selecionamos 148 produções e, a partir da leitura dos resumos, escolhemos aquelas que tivessem relação com Formação de Professores na área das Ciências e da Matemática. Obtivemos 27 produções, das quais elaboramos uma nuvem de palavras a partir dos resumos para que pudéssemos visualizar se estavam de acordo com os objetivos da busca.

O próximo critério que utilizamos foi a limitação de tempo em 6 anos, pois algumas das produções selecionadas eram anteriores à 1995 . Justificamos esse recorte de tempo por entender que as possiveis motivações 
em relação ao abandono da carreira docente ou da licenciatura sejam diferentes em tempos atuais, principalmente por terem ocorrido modificações no que tange a questão de investimentos na área da Educação por parte do Estado, e também porque ocorreram mudanças na sociedade e, consequentemente, na Educação. Assim, foram selecionados para a análise dezesseis produções, sendo oito sobre o abandono na licenciatura e oito sobre o abandono na docência.

Escolhemos realizar as análises evidenciando as relações de aproximação ou afastamento entre as principais contribuições das pesquisas, com vistas a compreensão em relação ao abandono da carreira docente. Ressaltamos que nem sempre foi possivel estabelecer pontos de aproximação devido a diversidade de ideias, concepções e resultados obtidos pelas produções. Optamos por esta forma de organização baseadas nas ideias de Ferreira (2002, p.9):

Um segundo momento é aquele em que o pesquisador se pergunta sobre a possibilidade de inventariar essa produção, imaginando tendências, ênfases, [...] aproximando ou diferenciando trabalhos entre si, na escrita de uma história de uma determinada área do conhecimento. Aqui, ele deve buscar responder, além das perguntas 'quando', 'onde' e 'quem' produz pesquisas num determinado período e lugar, àquelas questões que se referem a 'o quê' e 'o como' dos trabalhos.

Na sequência, estabelecemos o referencial teórico e, como ponto central de análise na elaboração deste estado de conhecimento, apontamos as confluências entre os principais resultados e contribuições das investigações.

\section{O Posicionamento Teórico: Formação e Abandono}

Para o desenvolvimento deste artigo consideramos, em cada nível de formação, as características da formação profissional tal como expresso por Tardif (2002), como uma formação que: apoia-se em conhecimentos especializados e formalizados construídos através de uma longa formação; são é essencialmente pragmático; pertence aos profissionais que têm a 
competência e o direito de usar seus conhecimentos e ainda avaliar o trabalho dos seus pares; preconiza a autonomia em relação aos conhecimentos técnicos, o que exige dos profissionais uma construção de julgamento em situações de ação; considera os conhecimentos teóricos e práticos evolutivos e progressivos, necessitando de formação contínua; ainda preconiza a responsabilidade sobre os erros cometidos no exercício da profissão. Ou seja, a formação profissional é composta por um conjunto de atividades cuja finalidade é a construção de conhecimentos e saberes acerca das exigências para o exercício de uma atividade profissional.

Em relação à profissão docente, os saberes necessários para o exercício da profissão podem ser enunciados a partir das ideias de Tardif (2002), que considera o conhecimento profissional docente como um saber plural, constituído de diversos saberes: o profissional, que é construído nas instituições de formação de professores; os disciplinares, que emergem da tradição cultural; curriculares, que são os conhecimentos descritos nos programas escolares; os experienciais, resultantes de sua prática cotidiana. Para o autor, o professor precisa ter capacidade de dominar e integrar esses saberes por serem condição básica para o desenvolvimento de sua prática. Por isso, evidencia que a trajetória pessoal, a experiência na condição de aluno de graduação e a interação em sala de aula e com outros profissionais são elementos estruturantes na constituição da epistemologia da profissão docente.

Da mesma forma, Fazenda (2001, p. 226) considera que a formação de professores demanda o "[...] reconhecimento das trajetórias próprias dos homens e mulheres, bem como exige a contextualização histórica dessas trajetórias, assumindo a provisoriedade de propostos de formação de determinada sociedade". Seguindo a mesma linha de raciocinio, Cunha (1994) traz a opinião de professores em relação ao que seria o ideal na tarefa de um formador de docentes. Os pontos confluentes perpassam aspectos em relação ao gostar de ensinar, dominar o conteúdo e interpretá-lo a partir dos pontos de vista histórico e social, ter disponibilidade para permanecer estudando, até 
características em relação a condutas morais e afetivas no trato do conhecimento e do discente. Para a autora, a visão dos docentes sobre o ideal de bom professor "[...] assume uma fundamental importância para aqueles que estão envolvidos com a educação, que estão preocupados em intervir no processo de formação de professores na perspectiva da transformação social”. (CUNHA, 1994, p. 129).

Essa transformação social inerente ao exercício profissional também tem relação direta com o principal sujeito da atividade docente, que é o aluno. Charlot (2012) apresenta a discussão de que a formação de professores precisa ser desenvolvida baseada em questionamentos que o docente deve fazer em relação aos seus alunos: o aluno tem ou não atividade intelectual? Qual o sentido para o aluno dessa condição, de ter ou não atividade intelectual? Qual o prazer que o aluno pode encontrar na atividade intelectual? Além disso, o professor precisa refletir sobre as suas concepções em relação aos seus alunos nos meios populares, no sentido de dar-lhe condições, independentemente de sua origem social, de desenvolver sua capacidade intelectual.

Já Libâneo (2012) vai além, e considera que é necessário buscar mais do que apenas suporte pedagógico na formação dos professores, potencializando competências em direção ao pensar e observar criticamente a realidade. Para o autor:

Pensar é mais do que explicar, e para isso, as instituições precisam formar sujeitos pensantes, capazes de um pensar epistêmico, ou seja, sujeitos que desenvolvam capacidades básica em instrumentação conceitual que lhes permitam, mais do que saber coisas, mais do que receber uma informação, colocar-se frente a realidade, apropriar-se do momento histórico de modo a pensar historicamente essa realidade e reagir a ela. (LIBÂNEO, 2012, p. 85).

Assim, a partir das concepções dos autores, acreditamos que a formação de professores é um processo que ocorre de forma dinâmica ao longo de toda trajetória do docente, sendo influenciada por questões de ordem interna, como vontade de permanecer aprendendo e preocupação com o 
discente, além de receber influência do contexto histórico e social em que esse desenvolvimento acontece.

Porém, essas questões que influenciam a formação profissional, tanto inicial quanto continuada, podem promover momentos de tensão e dificuldade, ocasionando, por vezes, o abandono da profissão, seja antes do ingresso ou até com algum tempo de docência. Esse abandono também será denominado, neste artigo, de evasão.

Consideramos, neste artigo, a evasão como o ato de evadir-se, de fuga ou saída. Ou seja, é um ato de abandonar ou fugir de algo a que antes havia se proposto realizar. No que tange a licenciatura, esse abandono pode ser considerado como uma interrupção em um determinado ciclo de estudos (GAIOSO, 2005). A baixa procura pela licenciatura, somada aos altos índices de evasão nestes cursos, principalmente na área das Ciências e Matemática, evidencia que a falta de atratividade para a sala de aula gerou uma crise na Educação (GOMES, 1998). Não é dificil encontrar licenciandos e mesmo docentes, principalmente da Educação Básica, que expressam em seus discursos os vários descontentamentos com a profissão. Essa crise na Educação afeta, principalmente, os profissionais da sala de aula, gerando um mal-estar que tende a prolongar-se. (NÓVOA, 1998).

Huberman (2000) especifica algumas fases que determinam o ciclo de vida da profissão docente, das quais destacamos a fase denominada de entrada na carreira, na qual são tratadas as questões de sobrevivência ao início da profissão, perpassando características como as motivações e os enfrentamentos cotidianos em sala de aula. É nessa fase, durante os três primeiros anos na sala de aula, que o professor muitas vezes sente-se frustrado, pois observa certa ineficiência no estabelecimento da ligação entre a sua prática e o efetivo aprendizado discente. Tal afirmação entra em concordância com os estudos de Lapo e Bueno (2003), ao apontarem, por meio de diversas pesquisas, que o maior índice de evasão docente ocorre até o quinto ano de ingresso na profissão. Além disso, os baixos salários, os planos de carreira pouco estruturados e a baixa valorização social da profissão 
também são fatores de desmotivação para aquele que está na docência, bem como da opção profissional dos jovens que poderiam escolher ser professores. (GATTI; BARRETO, 2009).

A preocupação com o abandono da docência não é recente. De acordo com Lapo e Bueno (2002), no período de 1990 a 1995 foi registrado um aumento de $300 \%$ nos pedidos de exoneração na rede pública de São Paulo. As autoras avaliam o abandono da profissão docente como resultado dos baixos salários e das condições de trabalho diárias péssimas.

Já para Zagury (2006), depois de realizar pesquisa com um grupo de 1172 professores atuantes, em 22 estados brasileiros, não há nenhuma dúvida de que as principais tensões docentes estão centradas no maior problema atual em sala de aula, que é a indisciplina discente, independente do tempo, nivel de atuação e de formação do profissional. Além disso, questões como a motivação do aluno para o aprendizado, a preocupação com a avaliação e em manter-se atualizado surgem como outras dificuldades enfrentadas cotidianamente, o que vai ao encontro das ideias apresentadas pelos demais autores, quando destacam os motivos que levam à evasão docente.

Saltini, Vidal e Sobrinho (2014) explicam que a evasão na profissão docente ocorre por motivações internas e externas ao profissional. Contudo, os autores dão ênfase à baixa atratividade na carreira por conta de que "[...] avanços na área educacional não se concretizam, apesar dos discursos oficiais", e complementam afirmando que a desvalorização do professor é “[...] uma construção social e cultural de governos e da mídia para explicar o fracasso do Estado e do aluno". (SALTINI; VIDAL; SOBRINHO, 2014, p. 103).

Assim, de acordo com os estudos apontados acima, a permanência na licenciatura e/ou na profissão está relacionada a diferentes aspectos, tais como, a formação de qualidade, tanto inicial quanto continuada, a valorização salarial e o estabelecimento de política públicas que incentivem e tornem a profissão atraente. O que se espera, portanto, é uma formação profissional efetiva e condições favoráveis para que os docentes se encaminhem e 
permaneçam no exercício da docência.

Diante do exposto, apresentamos, na sequência, o estado de conhecimento sobre abandonos ocorridos na trajetória profissional docente.

\section{O Estado de Conhecimento das Pesquisas Acadêmicas sobre o Abandono na Docência e o Abandono na Licenciatura}

\section{A organização}

A organização das pesquisas acadêmicas oriundas do levantamento realizado nos portais já mencionados possibilitou a construção do estado de conhecimento. Na etapa da organização, em que foram selecionados 27 trabalhos, criamos uma nuvem de palavras, resultante do wordle, a partir dos resumos dessas produções.

\section{Figura 1 - Nuvem de palavras}

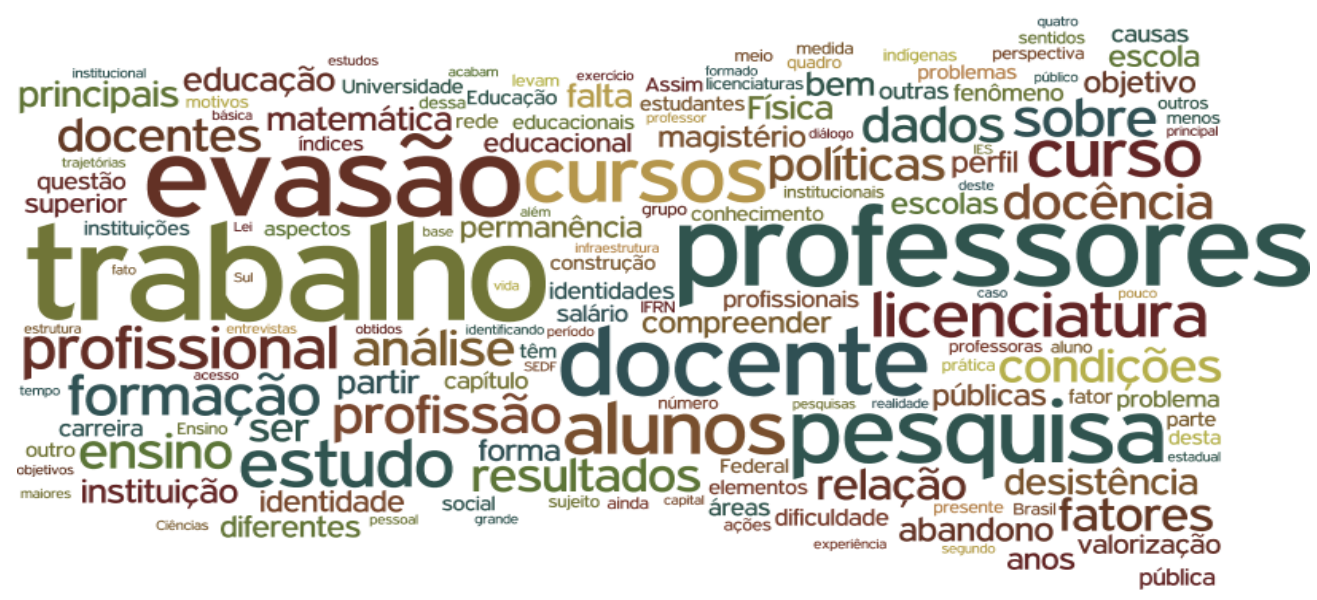

Fonte: Elaborado pelas autoras a partir do wordle.

Por meio da elaboração da nuvem, foi possível identificar que as palavras com maior frequência presentes nos resumos evidenciam os temas de interesse dessa pesquisa, que são evasão, licenciatura, professores, docente, profissão, formação, dentre outras. Cabe destacar a importância dos resumos como indicadores para futuras pesquisas. Portanto, no momento da 
leitura, a seleção por documentos que estivessem de acordo com os objetivos foi fundamental para a continuidade das análises.

Posteriormente, selecionamos as pesquisas de acordo com o ano de publicação, delimitando os últimos seis anos. Assim, obtivemos 16 produções acadêmicas e realizamos a leitura minuciosa das mesmas, visando identificar os principais elementos de cada produção e mantendo o foco nos resultados e contribuições.

Optamos por organizar os trabalhos selecionados em um quadro onde constam o nível da produção, o autor, o título e a Instituição de Ensino Superior ou Revista de publicação. Escolhemos as siglas An para artigo, Dn para Dissertação e Tn para Tese, nos quais $n$ é a numeração do tipo de documento.

\section{Quadro 1 - Produções científicas sobre a evasão na licenciatura}

\begin{tabular}{|c|c|c|c|c|}
\hline Sigla & Ano & Autor & Titulo & Instituição \\
\hline A1 & 2014 & $\begin{array}{l}\text { CARVALHO, Camila; } \\
\text { OLIVEIRA, Vitor } \\
\text { Wagner Neto de }\end{array}$ & $\begin{array}{l}\text { Evasão na Licenciatura: estudo de } \\
\text { caso }\end{array}$ & $\begin{array}{l}\text { Revista } \\
\text { Trilhas da } \\
\text { História }\end{array}$ \\
\hline A2 & 2013 & $\begin{array}{l}\text { OLIVEIRA, Bruna } \\
\text { Mendes; ANJOS, } \\
\text { Hellen Vivian } \\
\text { Moreira dos; } \\
\text { RODRIGUES, } \\
\text { Fernando Barreto }\end{array}$ & $\begin{array}{l}\text { Formação de Professores em } \\
\text { Institutos Federais e a evasão } \\
\text { como agravante da problemática } \\
\text { docente: o caso das licenciaturas } \\
\text { no Instituto Federal do Norte de } \\
\text { Minas Gerais - Campus Salinas }\end{array}$ & $\begin{array}{l}\text { II Colóquio } \\
\text { Nacional: } \\
\text { A Produção } \\
\text { do } \\
\text { Conhecimento } \\
\text { em Educação }\end{array}$ \\
\hline D1 & 2011 & $\begin{array}{l}\text { GOMES, Fernando } \\
\text { Costa Fernandes }\end{array}$ & $\begin{array}{l}\text { A desistência de alunos na } \\
\text { licenciatura em Física no Instituto } \\
\text { Federal de Educação, Ciência e } \\
\text { Tecnologia do Rio Grande do Norte } \\
\text { (IFRN): causas e sugestões para o } \\
\text { combate }\end{array}$ & $\begin{array}{l}\text { Universidade } \\
\text { Federal do Rio } \\
\text { Grande do } \\
\text { Norte }\end{array}$ \\
\hline D2 & 2015 & $\begin{array}{l}\text { VENTURA, Rafael } \\
\text { Coelho }\end{array}$ & $\begin{array}{l}\text { Trajetórias profissionais de } \\
\text { egressos do curso de graduação } \\
\text { em Ciências Biológicas da UFRJ: } \\
\text { Um estudo sobre a (não) } \\
\text { atratividade da docência }\end{array}$ & $\begin{array}{l}\text { Pontificia } \\
\text { Universidade } \\
\text { Católica do } \\
\text { Rio de Janeiro }\end{array}$ \\
\hline D3 & 2013 & $\begin{array}{l}\text { VITELLI, Ricardo } \\
\text { Ferreira }\end{array}$ & $\begin{array}{l}\text { Evasão em cursos de licenciatura: } \\
\text { perfil do evadido, fatores } \\
\text { intervenientes no fenômeno }\end{array}$ & $\begin{array}{l}\text { Universidade } \\
\text { do Vale do Rio } \\
\text { dos Sinos }\end{array}$ \\
\hline
\end{tabular}




\begin{tabular}{|c|c|c|c|c|}
\hline D4 & 2014 & $\begin{array}{l}\text { SOTERO, Valéria } \\
\text { Rocha Lima }\end{array}$ & $\begin{array}{l}\text { Evasão nos cursos de licenciatura: } \\
\text { a visão de alunos desistentes }\end{array}$ & $\begin{array}{l}\text { Universidade } \\
\text { Cidade de São } \\
\text { Paulo }\end{array}$ \\
\hline D5 & 2014 & $\begin{array}{l}\text { GERBA, Raphael } \\
\text { Thiago }\end{array}$ & $\begin{array}{l}\text { Análise da evasão de alunos nos } \\
\text { cursos de licenciatura: estudo de } \\
\text { caso no Instituto Federal de } \\
\text { Educação, Ciência e Tecnologia de } \\
\text { Santa Catarina }\end{array}$ & $\begin{array}{l}\text { Universidade } \\
\text { Federal de } \\
\text { Santa } \\
\text { Catarina }\end{array}$ \\
\hline $\mathrm{T} 1$ & 2010 & $\begin{array}{l}\text { LEME, Helena } \\
\text { Alessandra Scavazza }\end{array}$ & $\begin{array}{l}\text { Formação superior de professores } \\
\text { indigenas de Matemática em Mato } \\
\text { Grosso do Sul: acesso, } \\
\text { permanência e desistência }\end{array}$ & $\begin{array}{l}\text { Universidade } \\
\text { de São Paulo }\end{array}$ \\
\hline
\end{tabular}

Fonte: As autoras.

\section{Quadro 2 - Produções científicas sobre a evasão na docência}

\begin{tabular}{|c|c|c|c|c|}
\hline Sigla & Ano & Autor & Titulo & $\begin{array}{c}\text { Instituição/ } \\
\text { Revista }\end{array}$ \\
\hline A3 & 2014 & $\begin{array}{l}\text { ENS, Romilda } \\
\text { Teodora; EYNG, Ana } \\
\text { Maria; GISI, Maria } \\
\text { Lourdes; RIBAS, } \\
\text { Marciele Stiegler }\end{array}$ & $\begin{array}{l}\text { Evasão ou permanência na } \\
\text { profissão: politicas educacionais e } \\
\text { representações sociais de } \\
\text { professores }\end{array}$ & $\begin{array}{l}\text { Revista } \\
\text { Diálogo } \\
\text { Educacional }\end{array}$ \\
\hline A4 & 2014 & $\begin{array}{l}\text { PALAZZO, Janete; } \\
\text { GOMES, Cândido } \\
\text { Alberto }\end{array}$ & $\begin{array}{l}\text { Professores de menos, licenciados } \\
\text { demais? }\end{array}$ & $\begin{array}{l}\text { Educação } \\
\text { Online }\end{array}$ \\
\hline A5 & 2014 & $\begin{array}{l}\text { SALTINI, Marcia } \\
\text { Regina; VIDAL, Aline } \\
\text { Gomes; SOBRINHO, } \\
\text { Afonso Soares } \\
\text { Oliveira }\end{array}$ & $\begin{array}{l}\text { Politicas públicas de educação e } \\
\text { precarização do trabalho em São } \\
\text { Paulo: o abandono da profissão } \\
\text { docente na rede pública estadual }\end{array}$ & $\begin{array}{l}\text { Trabalho \& } \\
\text { Educação }\end{array}$ \\
\hline D6 & 2010 & $\begin{array}{l}\text { MEIRA, Camila } \\
\text { Jardim }\end{array}$ & $\begin{array}{l}\text { Processos identitários docentes: } \\
\text { adesão e desistência }\end{array}$ & $\begin{array}{l}\text { Centro } \\
\text { Federal de } \\
\text { Educação } \\
\text { Tecnológica } \\
\text { de Minas } \\
\text { Gerais }\end{array}$ \\
\hline D7 & 2013 & $\begin{array}{l}\text { FONSECA, Mônica } \\
\text { Padilha }\end{array}$ & $\begin{array}{l}\text { Porque desisti de ser professora: } \\
\text { um estudo sobre a evasão docente }\end{array}$ & $\begin{array}{l}\text { Universidade } \\
\text { de Brasília }\end{array}$ \\
\hline D8 & 2013 & $\begin{array}{l}\text { VIEIRA, Elisandra } \\
\text { Felix }\end{array}$ & $\begin{array}{l}\text { Sentidos e significados que } \\
\text { professores atuando em escolas de } \\
\text { periferia constituem para as } \\
\text { dificuldades e desafios encontrados } \\
\text { em sua profissão }\end{array}$ & $\begin{array}{l}\text { Pontificia } \\
\text { Universidade } \\
\text { Católica de } \\
\text { São Paulo }\end{array}$ \\
\hline D9 & 2015 & $\begin{array}{l}\text { SILVA, Roniel } \\
\text { Sampaio }\end{array}$ & $\begin{array}{l}\text { Quando a docência abandona os } \\
\text { professores: a evasão docente na } \\
\text { rede pública estadual de Rondônia }\end{array}$ & $\begin{array}{l}\text { Universidade } \\
\text { Federal de } \\
\text { Rondônia }\end{array}$ \\
\hline
\end{tabular}




\begin{tabular}{|c|c|c|c|c|}
\hline & & & $(2008-2012)$ & \\
\hline T2 & 2013 & PAZ, Mônica Lana da & $\begin{array}{l}\text { A permanência e o abandono da } \\
\text { profissão docente entre professores } \\
\text { de Matemática }\end{array}$ & $\begin{array}{l}\text { Universidade } \\
\text { Federal de } \\
\text { Minas Gerais }\end{array}$ \\
\hline
\end{tabular}

Fonte: As autoras.

\section{As Análises}

Nesta fase de análises, evidenciamos as aproximações e confluências entre os resultados e contribuições das pesquisas, organizadas em categorias de análise, que são apresentadas em itálico. Optamos por organizar as análises dividindo-as entre os porquês da evasão na licenciatura, seguido de algumas explicações explicitadas pela pesquisa sobre o abandono da docência.

\section{A evasão na licenciatura - alguns porquês...}

Ao analisar os resultados e contribuições das produções pudemos compreender quais são as principais circunstâncias que contribuem para que o acadêmico abandone os cursos de licenciatura nas áreas das Ciências e da Matemática. A seleção das pesquisas permeia resultados de diferentes instituições de ensino públicas, privadas e comunitárias, nas esferas federal e estadual. A partir de uma análise onde apontamos confluências entre os resultados das pesquisas, podemos afirmar que os autores: apresentam seus resultados apontando que as causas de abandono já são explicadas a partir da justificativa que os acadêmicos apontam por escolher a licenciatura; retratam um perfil do evadido ou daquele que possivelmente evadirá; evidenciam as causas pessoais do licenciando em relação ao abandono; discursam sobre o docente formador desses acadêmicos; discutem sobre as disciplinas ou considerações sobre o curso como causas de desistência; apresentam os problemas em relação à instituição de ensino; destacam a falta ou inadequação de políticas públicas; apresentam propostas para que o 
acadêmico permaneça na licenciatura.

Mas podemos questionar, porque escolhem a licenciatura? Ventura (2015) afirma que a escolha ocorre principalmente pela crença de que será possivel colocar-se no mercado de trabalho desde os primeiros anos da graduação, e também sinaliza que o desejo de tornar-se professor tem ligação com o sentimento de nobreza em relação ao caráter social da docência. Leme (2010), ao estudar os licenciandos indígenas, conclui que estes escolhem o curso - neste caso, a Matemática - pois acreditam que há a possibilidade de contextualizar o ensino em suas aldeias. O autor afirma, ainda, que o curso de Matemática não seria a primeira opção da maioria, mas a mais oportuna, com possibilidade de trabalho na aldeia desde os anos iniciais. Destaca, porém, que essas justificativas não são suficientes.

Em relação ao perfil dos licenciandos que evadem ou que correm o risco de evadir, Gomes (2011) os descreve como sendo predominantemente do sexo feminino, casados e com filhos, trabalhadores e que concluíram o ensino médio há pelo menos seis anos. Já Vitelli (2013) aponta que o perfil do estudante que tem alto risco de evasão está classificado por conta de quatro fatores principais: econômicos, de desempenho, sociais e de escolha.

Sobre as principais razões que contribuem para o abandono, Gomes (2011) traz, por meio de entrevistas, que as causas são pessoais como opção de ingresso em outro curso superior e falta de tempo para se dedicar ao curso. Sotero (2014) apresenta motivos particulares que levam ao abandono, sendo o fator financeiro o principal deles, seguido do interesse por outro curso e da dificuldade em conciliar os horários de estudo com os de trabalho. Da mesma forma, Gerba (2014) aponta que os fatores relevantes são a dificuldade em organizar os horários de estudo e trabalho, a possível baixa remuneração depois de formado e, ainda, a falta de valorização do profissional professor.

Em relação ao docente do curso de licenciatura, Carvalho e Oliveira (2014) afirmam que mesmo havendo uma melhora no quadro docente a nível nacional, a desistência dos acadêmicos continua crescendo, mostrando uma incoerência. Gomes (2011) também traz a opinião dos docentes em relação ao 
abandono na licenciatura. Na visão desses autores, a falta de interesse, a falta de dedicação e de integração no curso são os principais fatores de evasão discente. Tal interpretação acentua o fato de que o docente da graduação não assume responsabilidades e coloca toda a culpa da desistência naquele que tem a dificuldade: o acadêmico.

O curso e as disciplinas ofertadas nas grades também são motivos de desistência na licenciatura. Sotero (2011) afirma que problemas de relacionamento com a coordenação do curso e problemas em relação à infraestrutura são fatores de abandono, embora citados por um número menor de acadêmicos. Além disso, Sotero (2011) e Leme (2010) verificaram que dificuldades com as disciplinas e com o aprendizado de um conteúdo específico são motivos que também levam à desistência.

Destacado por Gerba (2014) e Sotero (2014) a instituição que (des)acolhe tem influência na decisão por deixar a licenciatura, seja em relação a problemas de infraestrutura, seja em relação à segurança oferecida pela instituição nos horários de entrada e saída das aulas.

Também são fatores que aumentaram a desistência na licenciatura algumas ações em relação a políticas públicas de ingresso e permanência em cursos superiores. Os resultados da pesquisa de Carvalho e Oliveira (2014) permitem concluir que houve um aumento nas desistências após a alteração do sistema de ingresso, substituindo o vestibular pelo Exame Nacional do Ensino Médio (ENEM) e Sistema de Seleção Unificado (SISU). Vitelli (2013) observa que as políticas públicas destinadas ao acesso e permanência na licenciatura não se mostram eficientes, analisando que a maior parte das propostas visa o acesso mas não foca na permanência deste aluno na licenciatura, como é o caso do Programa Universidade para Todos (PROUNI), revelando uma carência de propostas nesta área. Especificamente em relação aos indígenas, Leme (2010) discute a questão das cotas como política de acesso ao ensino superior, porém, da mesma forma que Vitelli (2013), observa que essa politica não consegue assegurar a conclusão do curso por este licenciando. 
Por fim, apontamos algumas recomendações indicadas pelos autores para que a evasão diminua. Gomes (2011) propõe a implementação de ações para melhorar o conhecimento de licenciandos em alguns conteúdos da educação básica e programas específicos para o aluno que precisa conciliar o curso superior com o seu trabalho. Gerba (2014) vai além, e sugere que é necessária uma intervenção junto à sociedade, no sentido de propor uma valorização da profissão docente. Além disso, propõe a inserção do licenciando no mercado de trabalho ainda na graduação, bem como o fortalecimento de programas de assistência estudantil. Já a readequação da estrutura curricular dos cursos é proposta por Oliveira, Anjos e Rodrigues (2013), Gerba (2014) e Gomes (2011).

\section{E na docência, quais são os porquês da evasão?}

Os resultados e contribuições para o âmbito das Ciências e Matemática elencadas pelas pesquisas que selecionamos e analisamos são muito variadas, mas todas com subsídios positivos. Optamos por apontar as confluências entre os resultados e contribuições a partir de uma organização desde condições macro até condições individuais que justificam o abandono da sala de aula: visão neoliberal de um Estado que não valoriza a Educação e, portanto, à docência; adversidades na formação inicial; problemas de

estrutura física e pedagógica das escolas; e, por fim, condições sociais ou particulares que afetam ou são afetadas pelo abandono da sala de aula. Identificamos que problemas relacionados ao desinteresse dos alunos e de suas famílias são pouco mencionados como resultados das pesquisas.

A principal contribuição evidencia uma situação que temos vivenciado nesses anos de magistério: o desinteresse do Estado pelas causas da Educação. Ens, Eyng, Gisi e Ribas (2014) afirmam que há, do ponto de vista político, falta de condições objetivas de trabalho para os docentes, o que gera não somente a desistência na docência, mas durante a licenciatura. Observam também que o abandono permeia problemas que vão desde a desvalorização, 
os baixos salários e a observação do pouco investimento dado à Educação. Palazzo e Gomes (2014) também destacam que os interesses e reformas neoliberais, expressos nas politicas dos governos que transferem a responsabilidade da gestão educacional do Estado exclusivamente para a escola vão ao encontro dos interesses docentes, o que culmina com o prejuízo e precarização do trabalho desenvolvido em sala de aula. Da mesma forma, Silva (2015) conclui que essa precarização do trabalho docente é de interesse do Estado e do Capital, na medida em que a evasão docente é positiva ao propiciar uma rotatividade de professores, por meio de contratos temporários, criando um "exército de reserva" e, consequentemente, o desemprego, o que fomenta o setor produtivo e incrementa o terceiro setor. Essa afirmativa vai ao encontro dos resultados apresentados por Pallazo e Gomes (2014), ao destacarem que pela desvalorização socioeducacional boa parte daqueles que cursam licenciatura não se dedicam ao magistério.

Também surgem como fortes fatores de abandono da sala de aula as questões relativas aos problemas de formação inicial, evidenciadas nos resultados das pesquisas de Palazzo e Gomes (2014), Vieira (2013) e Fonseca (2013). De acordo com essas pesquisas, existe uma enorme lacuna entre o pouco que é oferecido em nivel de formação inicial e o que é exigido no exercício profissional. Os autores também afirmam que não há, na formação inicial, a preocupação em discutir sobre as necessidades diárias inerentes à profissão, o que remete a um sentimento comum de incapacidade, gerando abandono. Ou seja, o professor tende a abandonar a docência pois não se sente preparado para assumir as responsabilidades que lhe são apresentadas. Em sua formação inicial, por problemas de tempo insuficiente e de pouco investimento do Estado, não houve uma formação sólida, inclusive no que se refere a conhecimentos científicos que estes precisam ensinar nas escolas.

Outra situação apontada como fator de abandono da docência refere-se aos problemas de estrutura física e pedagógica das escolas. As discussões de Fonseca (2013) indicam que as condições de trabalho estabelecidas a partir dos problemas de estruturas no funcionamento e na organização das escolas 
favorecem a descrença e consequentemente o abandono da sala de aula. Afirma, ainda, que o modelo de escola e de método de ensino são fatores de insatisfação docente, o que sugere um repensar a escola no que se refere a questões metodológicas e conceituais. Da mesma forma, Meira (2010) e Paz (2013) apontam para a revelação de tensões entre o que os professores imaginam ideal e o que eles têm de concreto no cotidiano escolar, ou seja, há um ideal de ensino, há um desejo de ensinar de uma maneira viva, porém, os obstáculos surgem em consonância com a precariedade na qual o sistema público escolar se encontra e impõe o trabalho do professor. Ens et al. (2014) também indicam que a evasão docente está relacionada a fatores como as atitudes dos alunos e a falta de condições de trabalho para o exercício da profissão.

Em relação aos problemas sociais ou particulares, que afetam ou são afetados pelo abandono da sala de aula, Meira (2010) indica que o envolvimento que ocorre entre o professor e à docência está relacionado à forma como estes veem a docência, a família, a infância, as histórias de suas vidas e de seus alunos, o que por vezes causa bem-estar, por outras, malestar profissional, suscitando adoecimentos, desgaste funcional e sentimentos de angústia e abandono. Da mesma forma, Paz (2013) aponta evidências de que conflitos internos entre as identidades profissionais a respeito das quais os professores ouvem e discursam e do que vivenciam, no cotidiano colaboram para o abandono da docência. Esse abandono docente tem se mostrado um problema social que afeta os alunos e a qualidade da educação do país, principalmente pública (SALTINI; VIDAL; SOBRINHO, 2014). Assim, além de sentirem-se invisiveis e despersonificados por conta de todos os problemas que os atingem, Fonseca (2013) observa que os professores se percebem como incapazes de sair do empírico e compreender suas posições históricas, políticas e econômicas, o que contribui para o empobrecimento da carreira do magistério.

Apenas o estudo de Paz (2013) faz um paralelo entre aquele que abandona e o que permanece na docência, justificando a permanência na 
docência, mesmo que de forma sofrida, como sendo uma circunstância da vida. Para a autora, permanecem na luta diária aqueles que dizem ter vocação profissional, não vislumbram atuar em outra profissão, observam na docência uma estabilidade de emprego e ainda consideram a docência como uma atividade rentável.

\section{Considerações Finais}

O objetivo inicial deste trabalho foi a construção do estado de conhecimento, de modo a compreender as (des)motivações que contribuem para o abandono da carreira docente, seja durante a atuação ou anterior à ela, já nos cursos de licenciatura. Finalizadas as análises, foi possível compreender algumas motivações que levam o licenciando a abandonar o curso ou o professor a abandonar a sala de aula, e acreditamos que conseguimos responder a problemática proposta, na medida em que foi possivel selecionar trabalhos em relação ao tema com contribuições significativas para a área da Educação, especialmente no que tange a formação e atuação docente.

Percebemos que, apesar de variadas, existem aproximações quanto aos abandonos que vêm ocorrendo na licenciatura, sendo as causas pessoais as mais citadas, desde dificuldades de horário e com as disciplinas até relacionamento com coordenador e problemas com a Instituição. O professor formador parece não ter consciência da importância de seu papel de incentivador, pois de acordo com as conclusões de uma das pesquisas, o problema da evasão recai sempre sobre o licenciando. Na condição de professoras formadoras, acreditamos que nossa atribuição na licenciatura deve ir além de simplesmente lecionar conteúdos científicos, mas estabelecer uma relação de parceria com o futuro professor, contribuindo para que ele se perceba como um profissional crítico, atuante e reflexivo.

Já na docência, o abandono perpassa justificativas desde o sucateamento do Estado em relação à Educação, estrutura física e 
pedagógicas inadequadas e também em relação ao sentimento de impotência ou não identificação com a docência.

A falta de políticas públicas que incentivem a permanência na licenciatura e na docência surge como fator comum, evidenciando que não basta abrir cursos, contratar professores e estabelecer condições de acesso à licenciatura ou à profissão docente. É preciso fornecer condições para que o acadêmico permaneça na licenciatura, vislumbrando um futuro promissor na docência ao observar que aqueles que já estão em sala de aula são valorizados e têm reais condições de desenvolver-se na profissão.

Ou seja, para que haja permanência tanto na docência quanto na licenciatura é necessário estabelecer políticas públicas no sentido de valorização profissional, formação inicial sólida e contínua de qualidade, além de adequação de estruturas física e pedagógica, tanto das Instituições de Ensino Superior quanto das escolas de Educação Básica.

Dessa forma, acreditamos que o problema proposto, sobre o que se tem produzido acerca do tema evasão na docência e evasão na licenciatura, e quais são as principais contribuições destes estudos na área das Ciências e da Matemática, foi satisfatoriamente respondido. Esperamos que a apresentação deste estado de conhecimento contribua para a reflexão sobre o tema da evasão na docência e nos cursos de formação de professores de modo a construir possiveis caminhos para superar esta problemática.

\section{Referências}

CHARLOT, B. Formação de professores: a pesquisa e a política educacional. In: PIMENTA, S. G; GHEDIN, E. (Org.) Professor reflexivo no Brasil: gênese e crítica de um conceito. 7. ed. São Paulo, SP: Cortez, 2012.

CUNHA, M. I. O bom professor e sua prática. Campinas, SP: Papirus, 1994.

FAZENDA, I. Dicionário em construção: interdisciplinaridade. São Paulo, SP: Cortez, 2001.

FONSECA, M. P. Porque desisti de ser professora: um estudo sobre a evasão docente. 2013. 135f. Dissertação (Mestrado em Educação) - Programa de 
Pós-Graduação em Educação Universidade de Brasília, Brasília, 2013. Disponivel em: <http://repositorio.unb.br/handle/10482/14201 >. Acesso em: 8 ago. 2017.

FERREIRA, N. S. A. As pesquisas denominadas estados da arte. Educação \& Sociedade, n. 79. 2002. Disponível em:

<http://www.scielo.br/pdf/es/v23n79/10857.pdf>. Acesso em: 14 abr. 2017.

GATTI, B. A.; BARRETO, E. S. Professores do Brasil: impasses e desafios. Brasilia, DF: UNESCO, 2009.

GOMES, A. A. Evasão e Evadidos: o discurso dos ex-alunos sobre evasão escolar nos cursos de licenciatura. 1998. 175f. Tese (Doutorado em Educação) - Programa de Pós-Graduação em Educação. Universidade Estadual Paulista, Marília,1998. Disponivel em: <https://repositorio.unesp.br/handle/11449/102247>. Acesso em: 5 jan. 2017.

HUBERMAN, M. O ciclo de vida profissional dos professores. In: NÓVOA, A. (Org.). Vida de professores. 2. ed. Porto: Porto Ed., 2000. p. 31-61.

LAPO, F. R.; BUENO, B. O. O abandono do magistério: vínculos e rupturas com trabalho docente. Psicologia, São Paulo, v. 13, n. 2, p. 243-276, 2002.

. Professores, desencanto com a profissão e abandono do magistério. Cadernos de Pesquisa, São Luís, n. 18, p. 65-88, 2003.

LIBÂNEO. J. C. Reflexividade e formação de professores: outra oscilação do pensamento pedagógico brasileiro? In: PIMENTA, S. G; GHEDIN, E. (Org.). Professor reflexivo no Brasil: gênese e crítica de um conceito. 7. ed. São Paulo, SP: Cortez, 2012.

MOROSINI, M. C. Estado de conhecimento e questões do campo científico. Revista Educação, Santa Maria, v. 40, n. 1, p. 101-116, 2015. Disponível em: <https://periodicos.ufsm.br/reveducacao/article/view/15822>. Acesso em: 2 fev. 2017.

NÓVOA, A. Relação escola - sociedade: "novas respostas para um novo problema". In: SERBINO, Raquel Volpato et al. (Org.). Formação de Professores. São Paulo, SP: Fundação Editora da UNESP, 1998.

ROMANOVSK, J. P.; ENS, R. T. As pesquisas denominadas do tipo "estado da arte” em educação. Revista Diálogo Educacional, Curitiba, v. 6, n. 19, p. 37-50, 2006. Disponivel em:

<http://www.redalyc.org/articulo.oa?id=189116275004>. Acesso em: 10 jun. 2017. 
SALTINI, M. R.; VIDAL, A. G.; SOBRINHO, A. S. O. Políticas públicas de educação e precarização do trabalho em São Paulo: o abandono da profissão docente na rede pública estadual. Trabalho \& Educação, Belo Horizonte, v. 2 3, n.1, p. 99-117, 2014.

TARDIF, M. Saberes docentes e formação profissional. 3.ed. Petrópolis, RJ: Vozes, 2002.

VITELLI, R. F. Evasão em cursos de licenciatura: perfil do evadido, fatores intervenientes no fenômeno. 2013. 124f. Dissertação (Mestrado) - Programa de Pós-Graduação em Educação, Universidade do Vale do Rio dos Sinos, São Leopoldo, 2013.

ZAGURY, T. O professor refém: para pais e professores entenderem por que fracassa a educação no Brasil. 4. ed. Rio de Janeiro, RJ: Recordá, 2006.

Recebido: 16 de agosto de 2017

Aceito: 10 de setembro de 2017

Publicado: 19 de setembro de 2017 